\title{
Welding Soundness of a Thick-Walled 9Cr-1Mo Steel
}

\author{
Woo-Seog Ryu ${ }^{a}$, Sung-Ho Kim, Dae-Whan Kim \\ Korea Atomic Energy Research Institute \\ P.O. box 105, Yuseong, Daejeon, Korea \\ wsryu@kaeri.re.kr, shkim7@kaeri.re.kr, dwkim1@kaeri.re.kr
}

Keywords: $9 \mathrm{Cr}-1 \mathrm{Mo}-1 \mathrm{~W}$, Narrow gap welding, tensile, impact

\begin{abstract}
High Cr ferritic/martensitic steels are demanded to join using favorable welding processes with economical and metallurgical advantages in order to apply to the thick-walled reactor pressure vessel of a very high temperature gas cooled reactor. Narrow gap welding technology was adopted to weld a thick-walled $9 \mathrm{Cr}-1 \mathrm{Mo}-1 \mathrm{~W}$ steel with thickness of $110 \mathrm{~mm}$. The welding integrity was checked by non-destructive examination, optical microscopy and hardness test, and the homogeneity through welding depth was checked by absorbed impact energy and tensile strength. The optimizing welding conditions resulted that a narrow U-grooved gap with almost parallel edges was sound in actual practice, and the coarse grain zone was minimized in the heat affected zone. The absorbed energy of $75 \pm 25 \mathrm{~J}$ through welding depth was acceptable in scatter band to check the uniformity through the welding depth. The ultimate tensile stress and yield stress were about the same through welding depth at $650 \pm 10 \mathrm{MPa}$ and $500 \pm 10 \mathrm{MPa}$, indicating no difference through welding depth. Elongation was also almost same through depth, and the fracture surface was appeared as a normal. The weld metal had similar mechanical properties to base metal. The upper self energy of weld metal was 194J, and the ductile-brittle transition temperature was $30^{\circ} \mathrm{C}$. The tensile behavior was the typical trend with temperature, and YS and UTS of weldment were slightly higher than base metal by nearly below 10\%. Thus, it concluded that the soundness of the narrow gap welding of a thick-walled 9Cr-1Mo-1 W steel was confirmed in terms of the welding uniformity through the depth and mechanical properties.
\end{abstract}

\section{Introduction}

High $\mathrm{Cr}$ steel is a candidate material for the reactor pressure vessel of a very high temperature gas cooled reactor (VHTR). 9Cr-1Mo ferritic/martensitic steels have been developed for ultra supercritical fossil power plants, and advanced technologies for a steel fabrication have improved the elevated temperature properties of ferritic/martensitic steels to make them comparable with austenitic stainless steels [1-3]. In addition, ASME Section III, subsection NH Code includes the ferritic/martensitic steel of Mod.9Cr-1Mo in the 2004 edition, thus 9Cr-1Mo type steels are attracting attention as candidate materials for Generation IV reactors. The thickness of reactor pressure vessel of VHTR may be above $100 \mathrm{~mm}$, so it is important to select the welding method for the sound weld of thick-wall vessel. Among many welding methods, narrow gap welding (NGW) techniques have many advantages such as reduction of fabrication time, improvement of dimensional accuracy and reduction of coarse grain zone in the heat affected zone (HAZ) [4,5]. The NGW equipment needs high demands on accuracy of positioning and manipulation of wire in the narrow gap and the optimizing welding parameters are required to avoid the higher tendency to forming fusion defects, because the narrow weld gap makes difficulty in repairing defects. In this paper, the NGW technique using a thick-walled $9 \mathrm{Cr}-1 \mathrm{Mo}-1 \mathrm{~W}$ steel is evaluated in points of metallurgical soundness, uniformity through welding depth and mechanical properties. 


\section{Narrow gap welding of a thick-wall 9Cr-1Mo-1W steel}

A thick-walled plate of a $9 \mathrm{Cr}-1 \mathrm{Mo}-1 \mathrm{~W}$ steel with thickness of $110 \mathrm{~mm}$ was cut from a forged shaft with diameter of $750 \mathrm{~mm}$. The forged shaft was made for a turbine rotor of the $593{ }^{\circ} \mathrm{C}$-grade USC fossil plant by the DHI. The material specification is the COST E (Grade 911). The material was melted by VIM (Vacuum Induction Melt) followed by ESR (Electro Slag Remelt) technologies. The heat treatments of the shaft after a forging process were done at $1050{ }^{\circ} \mathrm{C}$ for an annealing process, and a two-step tempering process.

Narrow gap welding was done with a joint type of single U Groove (Narrow Gap) according to the modified welding procedure of the COST E steel. At first, the bottom part was joined by the GTAW (Gas Tungsten Arc welding) through 25 passes. The interpass temperature was kept at $200 \sim 300^{\circ} \mathrm{C}$, and the shielding gas was pure $\mathrm{Ar}$ gas with a flow rate of $12 \sim 18 \mathrm{~L} / \mathrm{min}$. After welding the bottom part, the upper U-groove was joined by the SAW through 57 passes. The inerpass temperature was kept at $200 \sim 300^{\circ} \mathrm{C}$. The precision NGW equipment was worked without any trouble during the welding process, and exact manipulation of the welding wire produced an accurate welded block, as shown in Fig. 1. The post-weld heat treatment was carried out at $740 \sim 760^{\circ} \mathrm{C}$.

\section{Welding integrity assessment}

It is known that Type IV cracks are often formed at the boundary between HAZ and base metal in ferritic/martensitic steels. Radiographic examination was carried out according to ASTM Section V to check the integrity of welding. The Co-60 was used for the radioisotope source. The film was AGFA D7 Type II. All the interpretations of films were found to be acceptable.

Microhardness showed a typical welding behavior in Fig. 2. The hardness of weldment was higher than that of base metal, but the softening in the HAZ seemed not to be produced. In a conventional $\mathrm{V}$-groove welding technology of Mod.9Cr-1Mo steel, HAZ is the lowest area in hardness due to coarse grains [6]. The narrow U-grooved gap with almost parallel edges was sound in actual practice.

The metallographic observation also appeared that no crack was founded at fusion line, as shown in Fig. 3. The microstructures in the fusion zone were the columnar structure at a macroscopic appearance, and

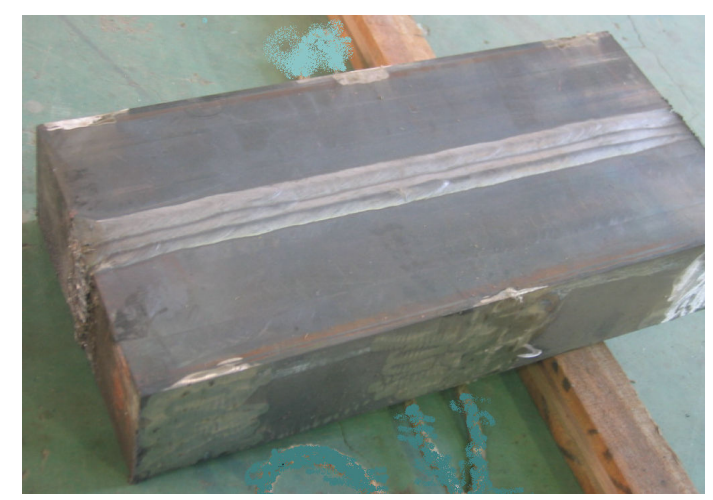

Fig. 1 Photo of the welded 9Cr-1Mo-1W

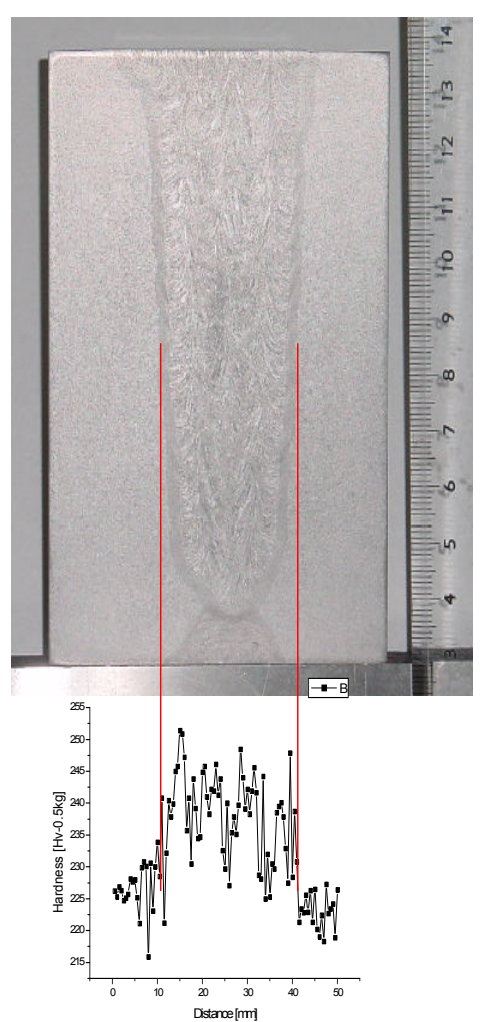

Fig. 2 Welding structure and microhardness

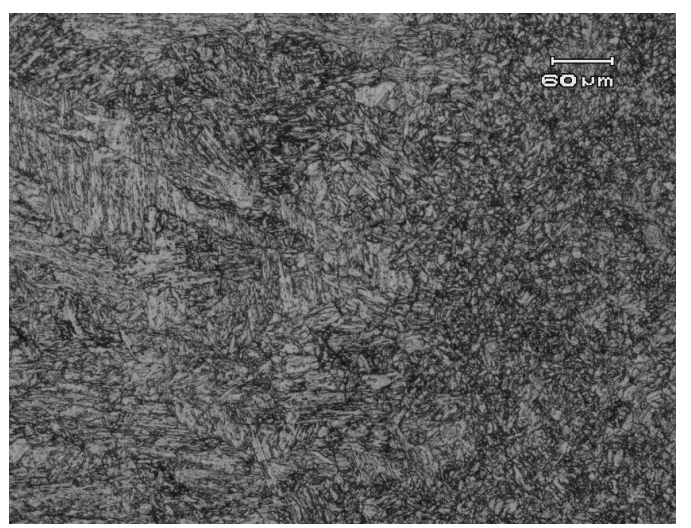

Fig. 3 Microstructure of fusion line 
the columnar was composed of the martensite lath at a microscopic examination. The HAZ showed the typical finer martensite structure than base metal. The optimizing welding conditions such as interpass temperature and heat input resulted in minimizing the width of HAZ of about $2.5 \mathrm{~mm}$, and reduced a coarse grain zone in the HAZ.

\section{Homogeneity through welding depth}

The narrow gap welding process used to the thick-walled 9Cr-1Mo-1W steel with $110 \mathrm{~mm}$ thickness was modified from conventional welding conditions of medium thick components for fossil power plants. So, it needed to confirm the uniform physical properties of the weldment through welding depth of the thick-walled component. Impact and tensile specimens were taken at 6 levels through welding depth.

Impact property was checked in terms of absorbed energy and lateral expansion at room temperature. Fig. 4 showed the absorbed energy of impact with position of welding depth. Position \#1 was located at upper, and \#6 was at bottom of the single U-grooved weldment. The absorbed energy of weldment was scattered in $75 \pm 25 \mathrm{~J}$. Considering general greater scatter in the ductile-brittle transition area at room temperature, the absorbed energy of $75 \pm 25 \mathrm{~J}$ through welding depth was acceptable to check the uniformity through the welding depth. The exceptional low value at position \#3 was attributed to improper fracture surface by inclusions at notch tip.

Tensile property showed little difference through welding depth as shown in Fig. 5. The ultimate tensile stress (UTS) at room temperature was about the same through welding depth at $650 \pm 10 \mathrm{MPa}$, and the yield stress was also about the same at $500 \pm 10 \mathrm{MPa}$. Fig. 6 shows that the elongation at room temperature was $13 \pm 0.5 \%$, indicating no difference through welding depth. These absorbed energy and tensile strength results illustrated the uniform physical properties through welding depth.

\section{Comparison between weldment and base metal}

Impact property is a key factor to determine the life reactor pressure vessel (RPV) in the surveillance program. Standard Chapy specimens machined from base and weld metals were tested according to ASME. Fig. 7 shows the typical tangent hyperbolic behavior of the absorbed energy as a function of temperature. The upper self energy (USE) of weldment was 194J, which was slightly lower than the USE of base metal of 216J.

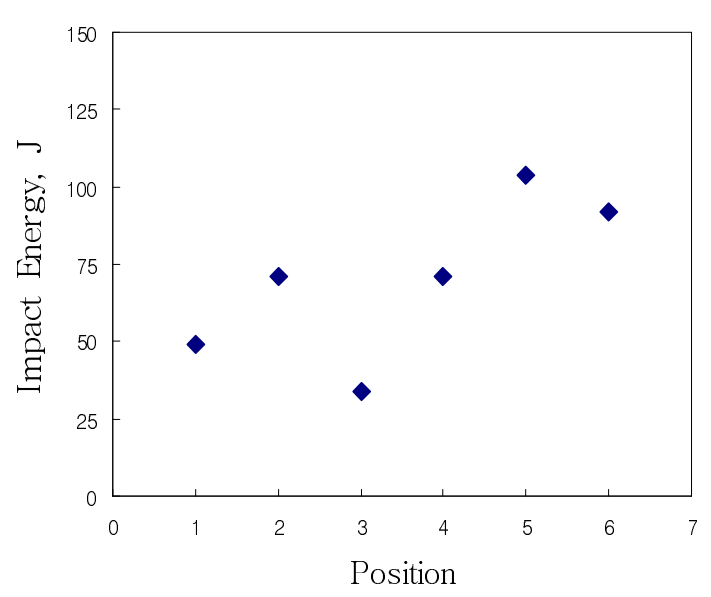

Fig. 4 Impact energy with welding depth

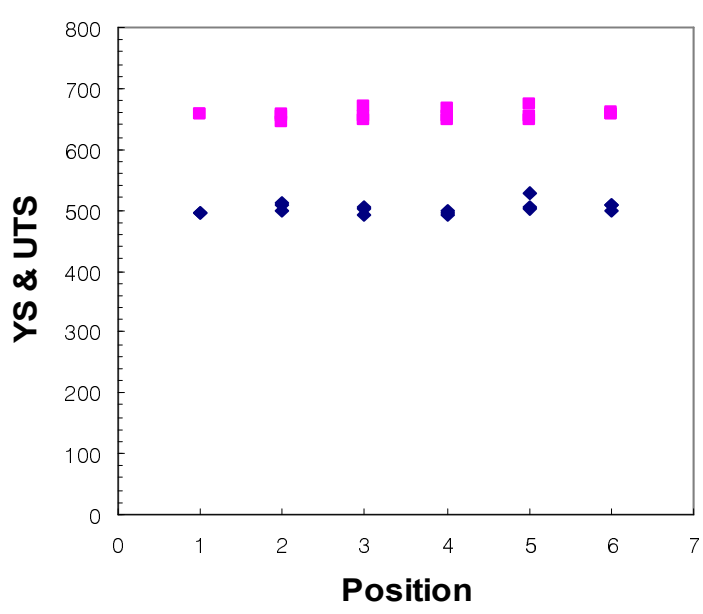

Fig. 5 YS \& UTS with welding depth

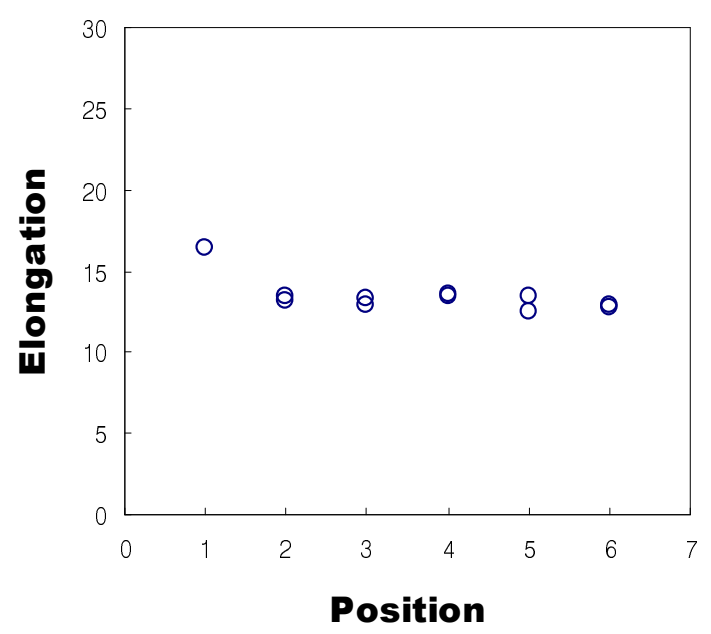

Fig. 6 Elongation with welding depth 
The temperature at $41 \mathrm{~J}$ of the weldment was $4^{\circ} \mathrm{C}$, below the room temperature, and the ductile-brittle transition temperature (DBTT) was $30^{\circ} \mathrm{C}$ higher than the DBTT of base metal of $-19^{\circ} \mathrm{C}$. The high DBTT of weldment seemed to be caused the dendrite structure, but it was proposed to improve the welding process. Tensile property is another important property for RPV. Fig. 8 shows the yield and ultimate tensile stresses as a function of temperature. The tensile behavior was the typical trend with temperature, and YS and UTS of weldment were slightly higher than base metal by nearly below $10 \%$.

\section{Summary}

The 9Cr-1Mo type ferritic/martensitic steels are the attracting candidate materials for the reactor pressure vessel of a very high temperature gas cooled reactor because of their good mechanical properties. The thickness of reactor pressure vessel above $100 \mathrm{~mm}$. required advanced welding technologies. The narrow gap welding technology was applied to join the thick-walled $9 \mathrm{Cr}-1 \mathrm{Mo}-1 \mathrm{~W}$ steel, and evaluated the welding soundness in terms of homogeneity through welding depth and mechanical properties. No defect was found in fusion line and the typical martensite structure with little coarse grain was observed in the heat affected zone. Through the welding depth, absorbed impact energy and tensile strength showed nearly uniform in scatter band. The weld metal had similar mechanical properties to base metal, though

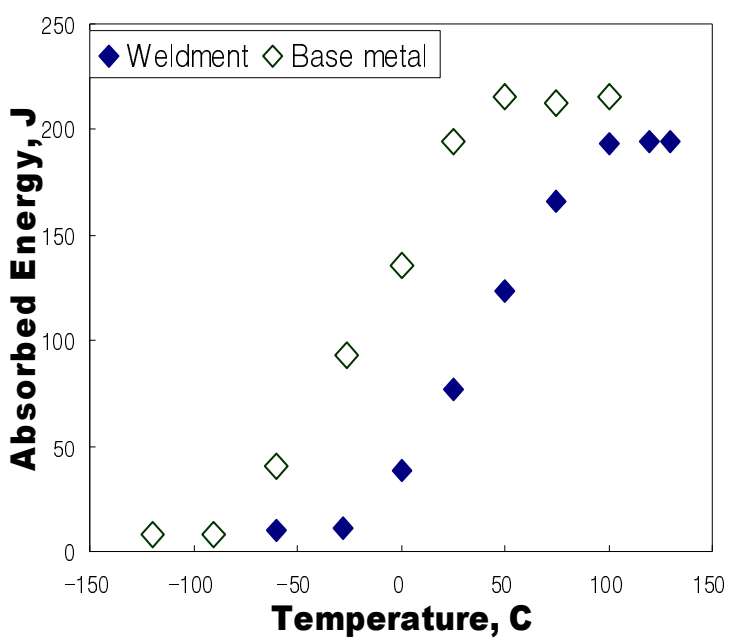

Fig. 7 DBTT curve with temperature

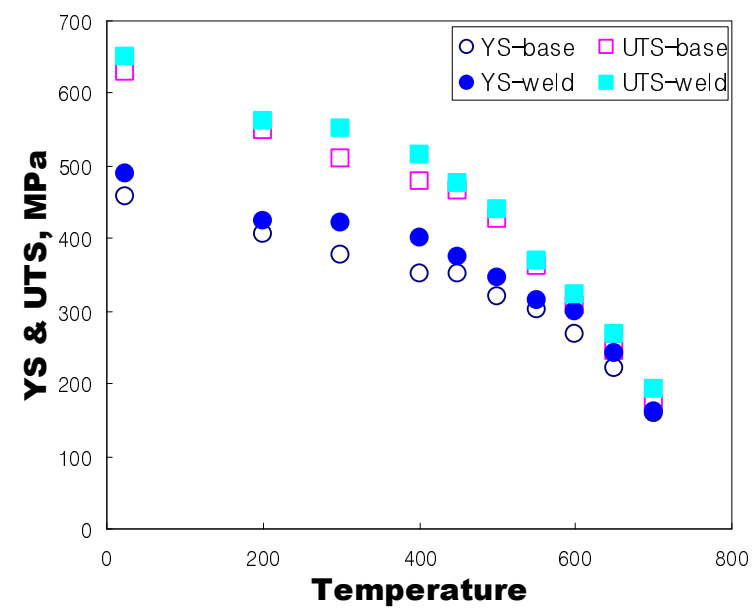

Fig. 8 YS \& UTS with temperature the ductile-brittle transition temperature of weld metal was near room temperature. These results concluded that the thick-walled $9 \mathrm{Cr}-1 \mathrm{Mo}-1 \mathrm{~W}$ steel was joined in success using a narrow gap welding technology.

\section{References}

[1] R.L. Klueh, Elevated-Temperature Ferritic and Martensitic Steels and Their Application to Future Nuclear Reactors, ORNL/TM-2004/176, Oak Ridge National Laboratory, USA(2004)

[2] R.L. Klueh and D. Harries, High-Chromium Ferritic and Martensitic Steels for Nuclear Applications, ASTM, West Conshohocken, USA(2001)

[3] W-S Ryu, S-H Kim and J-H. Hong, J. Nuclear Materials, v.329-333(2004), p.299

[4] H. Clausmeyer and H. Hantsch, Nuclear Engineering and Design, v.129(1991), p.255

[5] Cicero M.D. Starling, Paulo V. Marques and Paulo J. Modenesi, J. Materials Processing Technology, v.51(1995), p.37

[6] Woo-Seog Ryu, Sung-Ho Kim and Ji-Hyun Yoon, ICAPP 2008, USA(2008) 